\title{
Link between fluids and stable isotope disequilibrium between melt inclusions and host olivine
}

\author{
A.-S. BouvieR ${ }^{1 *}$, E.F. Rose-KogA ${ }^{2}$, A.R.L. NichOls ${ }^{3}$, \\ C. LE LAY ${ }^{1}$ \\ ${ }^{1}$ ISTE, University of Lausanne, Switzerland \\ (*correspondence: anne-sophie.bouvier@unil.ch) \\ ${ }^{2}$ LMV, Université Clermont Auvergne, France \\ ${ }^{3}$ School of Earth and Environment, University of Canterbury, \\ NZ
}

Stable isotope measurements in melt inclusions are scarce compared to those of major, trace and volatile elements, yet often record large variabilities that are interpreted as resulting from the influence of different fluids. SIMS investigation of the isotopic relationship between olivine-hosted melt inclusion (OHMIs) and their hosts in five arc samples revealed that $40 \%$ of the OHMIs are in isotopic disequilibrium $\left(\Delta^{18} \mathrm{Ool}\right.$-MI $)$ with their host [1]. New repeated random measurements of the composition of the host olivines reveal that they are homogeneous, within error, except for a few olivines in two samples that record a change of $\delta^{18} \mathrm{O}$ in their rims, and one olivine in which the $\delta^{18} \mathrm{O}$ also varies in its core. Major element mapping in this olivine reveals that it has undergone dissolution-reprecipitaiton. Interestingly, $\delta^{18} \mathrm{O}$ and $\mathrm{P}$ domains correlate, and the $\delta^{18} \mathrm{O}$ of the OHMIs is a mixture between the two major domains. In olivines with homogeneous $\delta^{18} \mathrm{O}$, isotopic disequilibrium with the host has been compared with geochemical fluid tracers measured in the OHMIs (e.g., $\mathrm{Sr} / \mathrm{Y}, \delta^{37} \mathrm{Cl}, \delta^{11} \mathrm{~B}$ ). Strong negative $\Delta^{18} \mathrm{O}_{\mathrm{Ol}}$ MI correlate with sediment influence indicators, whereas positive $\Delta^{18} \mathrm{O}$ Ol-MI record the influence of fluids from mafic lithologies. This link suggests that fluids were present at the time the OHMIs were trapped, and later homogenized with them. This hypothesis is supported by the presence of large holes in some polished olivines, sometimes associated with a small volume of glass. These holes suggest that in some cases, the fluids do not homogenize with the entrapped melt. The fluids could either originate from deeper melt lenses, releasing supercritical fluids, or from locally dehydrating crust.

\section{REFERENCES}

[1] Bouvier et al., Goldschmidt 2019, Abstract 358 